\title{
Assessment of Usefulness of CRP, PMN Elastase, PCT and II- 6 as Prognostic Factors in Patients with Acute Pancreatitis
}

\author{
B. Jagan Mohan Reddy ${ }^{\circledR 1}$, S.P. Girish ${ }^{\circledR 2}$ \\ ${ }^{1}$ Assistant Professor, Department of Surgical Gastroenterology, Sapthagiri Institute of Medical Sciences and Research Centre, Bangalore, Karnataka, India, ${ }^{2}$ Associate \\ Professor, Department of Surgical Gastroenterology, Sapthagiri Institute of Medical Sciences and Research Centre, Bangalore, Karnataka, India.
}

\section{Abstract}

Background: Acute pancreatitis is an inflammatory disease of the exocrine pancreas with rapid onset. The present study was conducted to assess the usefulness of CRP, PMN elastase, PCT and IL- 6 as prognostic factors in patients with acute pancreatitis. Subjects and Methods: The present study comprised 53 patients who presented with a diagnosis of Acute Pancreatitis. CRP was estimated by turbidimetric immunoassay using CRP/U2A-000 kit. PMN-Elastase was estimated by solid-phase enzyme immunoassay. Procalcitonin was estimated by the immunochromatographic test. IL-6 was estimated by Immuno-enzymatic assay. Results: There were 47 males and 6 females in the present study. The mean \pm SD CRP in patients with mild pancreatitis was $44.35 \pm 53.04$ and in severe pancreatitis was $174.80 \pm 14.55$, PCT was seen in 4 in mild pancreatitis patients and 12 in severe pancreatitis patients, PMN- elastase level was $3.89 \pm 1087$ in mild pancreatitis and $3.99 \pm 2.75$ inn severe pancreatitis patients, IL-6 level was $129.63 \pm 319.08$ in mild pancreatitis and $1166.76 \pm 818.06$ in severe pancreatitis patients. The difference was significant $(\mathrm{P}<0.05)$. CRP had higher (100) specificity as compared to PCT (81), PMN- E (10) and IL- 6 (90), Specificity found to be 88 , 81, 97 and 94 respectively, PPV was 84, 74, 67 and 90 respectively, NPV was 100, 87, 62 and 94 respectively, accuracy was $92,81,62$ and 92 respectively, AUC was $0.97,0.81,0.43$ and 0.95 respectively. Conclusion: Authors found that CRP is the single best predictor of the severity of acute pancreatitis. IL- 6 and PCT also are reliable predictors. PMN-Elastase needs to be assessed in patients with acute pancreatitis presenting early in the course of the illness.

Keywords: Acute Pancreatitis, PMN-Elastase, Markers

Corresponding Author: S.P. Girish, Associate Professor, Department of Surgical Gastroenterology, Sapthagiri Institute of Medical Sciences and Research Centre, Bangalore, Karnataka, India.

E-mail: girishsp2002@yahoo.co.in

Received: 02 August 2020

Revised: 11 September 2020

Accepted: 20 September 2020

Published: 27 December 2020

\section{Introduction}

Acute pancreatitis (AP) is an inflammatory disease of the exocrine pancreas with rapid onset, fast and uncontrollable progress, which ranges from self-limited disease to severer progressive disease with organ dysfunction and death. ${ }^{[1]} \mathrm{AP}$ may develop into severe acute pancreatitis (SAP) that is associated with multiple organ failure and systemic inflammatory response syndrome (SIRS). ${ }^{[2]}$ Acute pancreatitis is an inflammatory process that occurs in a normal organ and is diagnosed mainly by acute abdominal pain associated with a concomitant rise of serum amylase and lipase concentrations. Gallstone migration into the common bile duct and alcohol abuse accounts for most of the etiologies of the disease. Usually, the injury is mild, but $20 \%$ of the patients have a severe injury and, among them, 15 to $25 \%$ will die. ${ }^{[3]} \mathrm{C}$-reactive protein (CRP), a kind of inflammatory factor and a sensitive indica- tor for chronic inflammation diagnosis, is obviously increased in tissue damage and acute inflammation, being a marker reflecting inflammation. Procalcitonin (PCT) level is significantly increased in inflammation, infection, and organ failure, so it can be used as an evaluation index for infection. The main component of leukocytes in the peripheral blood of normal people is neutrophils, the ratio of which is significantly increased in inflammation and bacterial infection. ${ }^{[4]} \mathrm{IL}-$ 6 is the principal stimulus for acute-phase protein synthesis in the liver and constitutes the main mediator in the synthesis of fibrinogen, CRP, and hepcidin. The role of IL-6 in the early and accurate prediction of severity in AP was confirmed by numerous studies. ${ }^{[5]}$ PMN elastase is one of the serine proteases found in the granules of neutrophils. Granulocyte infiltration and activation which occurs as a first-line defense following tissue injury lead to the release of multiple microbicidal products, including reactive oxygen species, cationic peptides, 
eicosanoids and proteolytic enzymes. ${ }^{[6]}$ The present study was conducted to assess the usefulness of CRP, PMN elastase, PCT and IL- 6 as prognostic factors in patients with acute pancreatitis.

\section{Subjects and Methods}

The present study was conducted in the department of general surgery. It comprised of 53 patients with acute pancreatitis. Inclusion criteria were patients who present with acute pancreatitis within 72 hours of the onset of symptoms. Exclusion criteria were patients who presented more than 72 hours after the onset of symptoms. All patients were informed regarding the study and their consent was obtained. Ethical clearance was obtained before starting the study. A detailed history including presenting complaints, past illness, personal history, treatment history was taken including etiological risk factors. A detailed general and systemic examination were done. CRP was estimated by turbidimetric immunoassay using CRP/U2A-000 kit of 'APTEC Diagnostics NV'. The normal range was $0-6.7 \mathrm{mg} / \mathrm{L}$. PMN-Elastase was estimated by solidphase enzyme immunoassay using AESKULISA Elastase REF 3305 of AESKU Diagnostics, Germany. The normal range was $0-10 \mathrm{U} / \mathrm{ml}$. Procalcitonin was estimated by an immuno-chromatographic test using BRAHMS PCT-Q of BRAHMS, Henningsdorf. A value of $<0.5 \mathrm{ng} / \mathrm{ml}$ was taken as normal. IL-6 was estimated by an immuno-enzymatic assay using IL-6-EASIA-CE KAP 1261 of BIOSOURCE, Belgium. The normal range was $0-28 \mathrm{pg} / \mathrm{ml}$. Results were subjected to statistics.

\section{Results}

\begin{tabular}{|lll|}
\hline \multicolumn{3}{|c|}{ Table 1: } \\
\hline Gistribution of patients $(\mathbf{N}=\mathbf{5 3})$ \\
\hline Number & Males & Females \\
\hline
\end{tabular}

[Table 1] shows that there were 47 males and 6 females in the present study.

[Table 2], [Graph 2] shows that mean \pm SD CRP in patients with mild pancreatitis was $44.35 \pm 53.04$ and in severe pancreatitis was $174.80 \pm 14.55$, PCT was seen in 4 in mild pancreatitis patients and 12 in severe pancreatitis patients, PMN- elastase level was $3.89 \pm 1087$ in mild pancreatitis and $3.99 \pm 2.75$ inn severe pancreatitis patients, IL-6 level was $129.63 \pm 319.08$ in mild pancreatitis and $1166.76 \pm 818.06$ in severe pancreatitis patients. The difference was significant $(\mathrm{P}<$ $0.05)$.

[Table 3] shows that CRP had higher (100) specificity as compared to PCT (81), PMN- E (10) and IL- 6 (90), Specificity found to be $88,81,97$ and 94 respectively, PPV was $84,74,67$

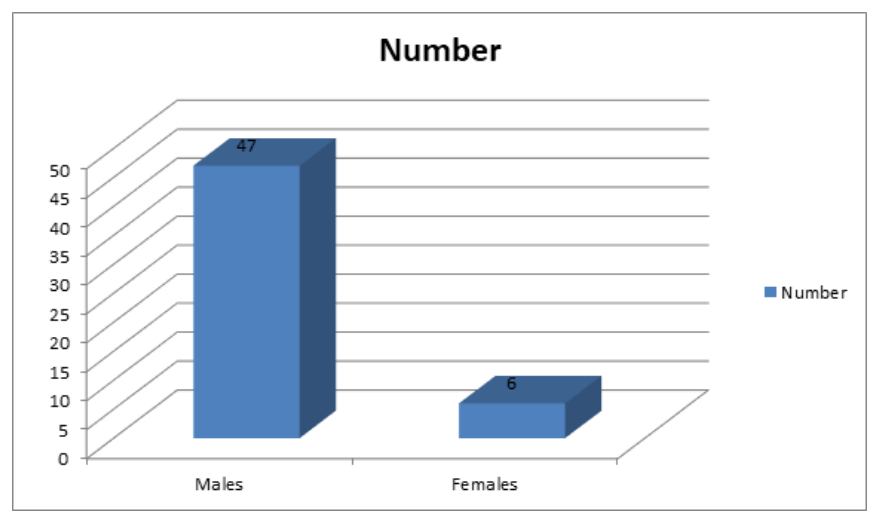

Figure 1: Distribution of patients

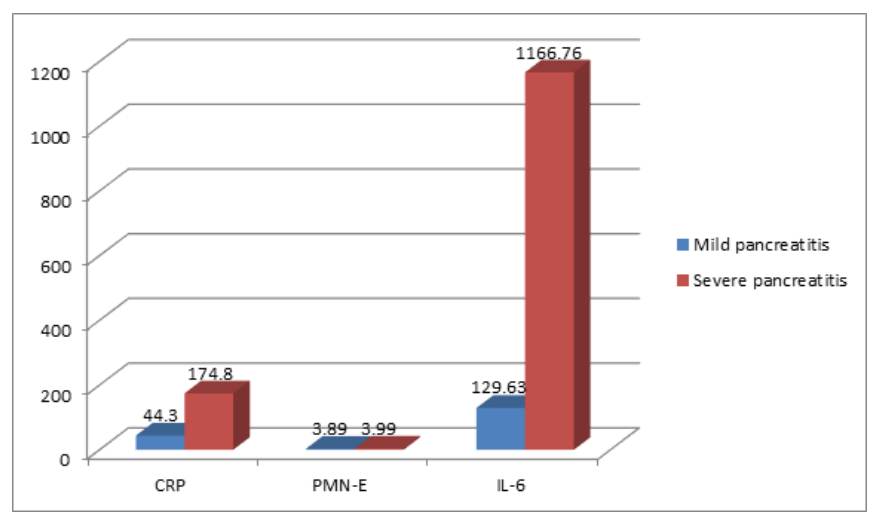

Figure 2: Assessment of CRP, PCT, PMN- E and IL- 6

and 90 respectively, NPV was 100, 87, 62 and 94 respectively, accuracy was 92, 81, 62 and 92 respectively, AUC was 0.97, $0.81,0.43$ and 0.95 respectively.

\section{Discussion}

The factors causing SAP are complex and closely related to bad living habits, gallstones, alcohol, etc. It has the characteristics of critical illness, many complications and a high fatality rate. ${ }^{[7]}$ Moreover, with the improvement of living standards, its incidence rate is increasing year by year. Although the vast majority of SAP patients can be cured without complications, as many as $25 \%$ of those hospitalized in ICU for 2 weeks, even after treatment, will suffer from serious complications or even death. Therefore, early diagnosis and evaluation of SAP are of great significance for the treatment and prognosis of patients. ${ }^{[8]}$ The present study was conducted to assess the usefulness of CRP, PMN elastase, PCT and IL- 6 as prognostic factors in patients with acute pancreatitis. In the present study, out of 53 patients, there were 47 males and 6 females in the present study. Liang 


\begin{tabular}{|llll}
\hline \multicolumn{2}{l}{ Table 2: Assessment of CRP, PCT, PMN- E and IL- $\mathbf{6}$} & & \\
\hline Variables (mean \pm SD) & Mild pancreatitis $(\mathbf{n}=\mathbf{3 2})$ & Severe pancreatitis $(\mathbf{n}=\mathbf{2 1})$ & P-value \\
\hline CRP & $44.35 \pm 53.04$ & $174.80 \pm 14.55$ & 0.000 \\
PCT $(\mathrm{n}, \%)$ & $4(12.50)$ & $12(57.14)$ & 0.001 \\
PMN-E & $3.89 \pm 1087$ & $3.99 \pm 2.75$ & 0.88 \\
IL-6 & $129.63 \pm 319.08$ & $1166.76 \pm 818.06$ & 0.00 \\
\hline
\end{tabular}

\begin{tabular}{|c|c|c|c|c|c|c|}
\hline Variables & Sensitivity & Specificity & PPV & NPV & Accuracy & AUC \\
\hline CRP & 100 & 88 & 84 & 100 & 92 & 0.9754 \\
\hline PCT & 81 & 81 & 74 & 87 & 81 & 0.8110 \\
\hline PMN- E & 10 & 97 & 67 & 62 & 62 & 0.4301 \\
\hline IL- 6 & 90 & 94 & 90 & 94 & 92 & 0.9539 \\
\hline
\end{tabular}

et al, ${ }^{[9]}$ explored the significance of procalcitonin (PCT), Creactive protein (CRP) and neutrophil ratio (N\%) in the early diagnosis, treatment, and prognosis of severe acute pancreatitis (SAP). A total of 104 patients with SAP (SAP group) and 101 patients with mild acute pancreatitis (MAP) (MAP group) were enrolled. The PCT and CRP in serum were detected by a full-automatic biochemical analyzer, and $\mathrm{N} \%$ in peripheral blood was measured by a hemocyte analyzer. The peripheral blood PCT, CRP, and N\% in the SAP group were significantly higher than those in the MAP group $(\mathrm{P}<0.001)$. Multivariate Logistic regression analysis showed that acute physiology and chronic health evaluation II (APACHE II) score, Ranson score, PCT, CRP, and N\% were independent risk factors for SAP. The receiver operating characteristic (ROC) curve showed that the area under the curve (AUC) of PCT, CRP, and N\% in diagnosing SAP was $0.906,0.840$, and 0.834 respectively, while that of combined detection was 0.972. The AUC of PCT, CRP, and N\% in diagnosing SAP death was 0.907, 0.900, and 0.894 , respectively. We found that mean \pm SD CRP in patients with mild pancreatitis was $44.35 \pm 53.04$ and in severe pancreatitis was $174.80 \pm 14.55$, PCT was seen in 4 in mild pancreatitis patients and 12 in severe pancreatitis patients, PMN- elastase level was $3.89 \pm 1087$ in mild pancreatitis and $3.99 \pm 2.75$ inn severe pancreatitis patients, IL-6 level was $129.63 \pm 319.08$ in mild pancreatitis and $1166.76 \pm 818.06$ in severe pancreatitis patients. The difference was significant $(\mathrm{P}<0.05)$. Blamey et $\mathrm{al}^{[10]}$ have shown the sensitivity of $100 \%$ of IL- 6 , NPV of $100 \%$ by using a cut-off of 130 . The overall accuracy came down from $83 \%$ with a cutoff of 130 to $75 \%$ when a cut of 120 was used. Imrie et ${ }^{a l},{ }^{[11]}$ have studied the time kinetics of changes in plasma concentrations of PMN-Elastase, various cytokines and acute phase reactants in acute pancreatitis. Their study has shown PMN-E reaches its maximum concentration early on the first day and gradually decreases thereafter. Most of the patients in our study presented beyond 12-16 hours from the onset of symptoms. Hence, PMN-Elastase may probably be of benefit in those patients who present very early in the course of pancreatitis. CRP had higher (100) specificity as compared to PCT (81), PMN- E (10) and IL- 6 (90), Specificity found to be $88,81,97$ and 94 respectively, PPV was $84,74,67$ and 90 respectively, NPV was 100, 87, 62 and 94 respectively, accuracy was $92,81,62$ and 92 respectively, AUC was 0.97 , $0.81,0.43$ and 0.95 respectively. Kylanpaa-Back et al, ${ }^{[12]}$ using a strip test, evaluated PCT on day 0 and day 1 and showed a sensitivity of $92 \%$ with an NPV as high as $97 \%$. This Finnish study is probably the only recent study that has shown PCT to be superior to CRP in predicting the severity of AP.

\section{Conclusion}

The authors found that CRP is the single best predictor of the severity of acute pancreatitis. IL-6 and PCT also are reliable predictors. PMN-Elastase needs to be assessed in patients with acute pancreatitis presenting early in the course of the illness.

\section{References}

1. Yadav D, Ng B, Saul M, Kennard ED. Relationship of Serum Pancreatic Enzyme Testing Trends With the Diagnosis of Acute Pancreatitis. Pancreas. 2011;40(3):383-389. Available from: https://dx.doi.org/10.1097/mpa.0b013e3182062970.

2. Banks PA, Bollen TL, Dervenis C, Gooszen HG, Johnson $\mathrm{CD}$, Sarr MG, et al. Classification of acute pancreatitis2012: revision of the Atlanta classification and definitions by international consensus. Gut. 2013;62(1):102-111. Available from: https://dx.doi.org/10.1136/gutjnl-2012-302779.

3. Wu BU, Johannes RS, Sun X, Tabak Y, Conwell DL, Banks PA. The early prediction of mortality in acute pancreatitis: a large population-based study. Gut. 2008;57(12):1698-1703. Available from: https://dx.doi.org/10.1136/gut.2008.152702.

4. Uhl W, Isenmann R, Curti G, Vogel R, Beger HG, Buchler MW. Influence of Etiology on the Course and Outcome of Acute 
Pancreatitis. Pancreas. 1996;13(4):335-343. Available from: https://dx.doi.org/10.1097/00006676-199611000-00002.

5. Gullo L, Migliori M, Oláh A, Farkas G, Levy P, Arvanitakis C, et al. Acute Pancreatitis in Five European Countries: Etiology and Mortality. Pancreas. 2002;24(3):223-227. Available from: https://dx.doi.org/10.1097/00006676-200204000-00003.

6. Swaroop VS, Chari ST, Clain JE. Severe acute pancreatitis. JAMA. 2004;291:2865-2868.

7. Otsuki M, Takeda K, Matsuno S. Criteria for the diagnosis and severity stratification of acute pancreatitis. World J Gastroenterol. 2013;19(35):5798-5805. Available from: https: //dx.doi.org/10.3748/wjg.v19.i35.5798.

8. Bereanu AS, Sava M. Correlation between Intra-Abdominal Pressure and C- Reactive Protein in Acute Pancreatitis. Acta Medica Transilvanica. 2015;20(4):109-113.

9. Liang Y, Zhao X, Meng F. Procalcitonin, C-reactive Protein, and Neutrophil Ratio Contribute to the Diagnosis and Prognosis of Severe Acute Pancreatitis. Iran J Public Health. 2020;48(12):2177-2177. Available from: https://dx.doi.org/10. 18502/ijph.v48i12.3548.

10. Blamey SL, Imrie CW, O'Neill J, Gilmour WH, Carter DC. Prognostic factors in acute pancreatitis. Gut. 1984;25(12):1340-1346. Available from: https://dx.doi.org/10. 1136/gut.25.12.1340. doi:10.1136/gut.25.12.1340.

11. Imrie CW, Benjamin IS, Ferguson JC, McKay AJ, Mackenzie I, O'Neill J, et al. A single-centre double-blind trial of
Trasylol therapy in primary acute pancreatitis. Br J Surg. 1978;65(5):337-341. Available from: https://dx.doi.org/10. 1002/bjs.1800650514.

12. Buxbaum J, Quezada M, Chong B, Gupta N, Yu CY, Lane C, et al. The Pancreatitis Activity Scoring System predicts clinical outcomes in acute pancreatitis: findings from a prospective cohort study. Am J Gastroenterol . 2018;113(5):755-764. Available from: https://dx.doi.org/10.1038/s41395-018-00481.

Copyright: (c) the author(s), 2020. It is an open-access article distributed under the terms of the Creative Commons Attribution License (CC BY 4.0), which permits authors to retain ownership of the copyright for their content, and allow anyone to download, reuse, reprint, modify, distribute and/or copy the content as long as the original authors and source are cited.

How to cite this article: Reddy BJM, Girish SP. Assessment of Usefulness of CRP, PMN Elastase, PCT and Il- 6 as Prognostic Factors in Patients with Acute Pancreatitis. Acad. J Surg. 2020; $3(2): 1-4$

DOI: dx.doi.org/10.47008/ajs/2020.3.2.1

Source of Support: Nil, Conflict of Interest: None declared. 